\title{
The Influence of Self-Compassion and Coping Strategies to Subjective Well-Being of Parents with Intellectual Disabled Children
}

\author{
Neneng Tati Sumiati \\ Faculty of Psychology \\ UIN Syarif Hidayatullah Jakarta \\ Jakarta, Indonesia \\ E-mail: neneng.tati@uinjkt.ac.id
}

\begin{abstract}
The presence of children with special needs, as intellectual disability, will affect various aspects of life in the family. For parents of the children with intellectual disability, responsibilities as parents and negative view of the community are a challenge. This condition certainly would affect subjective well-being of the parents and the children. This research is focused on scrutinizing subjective well-being on the parents of children with intellectual disability associated with parents' ability regarding self-regulation which is reflected in self-compassion and their ability to use coping strategies. The research was conducted on 136 parents of children with intellectual disability in Jakarta and South Tangerang with the accidental sampling method. The validity of instrument used technique confirmatory factor analysis (CFA). The data analysis used model path analysis using software M-Plus 7.4. The research results found that self-compassion as variable moderator between $\mathrm{PFC}$ and EFC to SWB were fit of the data. PFC was significant effect to SWB both direct effect $(r=0.272 ; p=0.023<0.05)$ and indirect effect $(r=0.168 ; p=0.005<0.05)$. On the other hand, EFC was significant to SWB only on direct effect $(r=-0.250$; $p=0.033<0.05$ ) but it was not significant on indirect effect $(r=0.098 ; p=0.078>0.05)$. This outcome indicates the parents need to have self-compassion and coping strategies focusing on the problem for it to be subjective well-being they maintained well.
\end{abstract}

Keyword: Intellectual disability, subjective well-being, selfcompassion, coping strategies

\section{INTRODUCTION}

Intellectual disability as one of children with special need's condition occurred in a quite number of cases. More than $15 \%$ of world's population are people with intellectual disabilities [1]. There are about 250 thousands of inhabitants in Indonesia are people with intellectual disabilities[2]. According to statistics Indonesia this number increases every year [2].

Lack of cognitive function becomes a serious problem for children with intellectual disability. It's difficult for them to adapt in the neighborhood, moreover for those who also have neuropsychiatric syndrome and organ system malfunction. This cognitive function deficiency also causes limitation in communication skill, social and academic that make them almost fully depend on their care giver [3]. Children with intellectual disability often get negative stigma such as being an object of bullying and alike. In certain society their condition are believed as a curse or punishment from God to the subjects' family therefore they have to be exiled [4].

Several attitude's problems experienced by children with intellectual disability cause the increasing the level of stress to their parents. The research result indicates the more maladaptive behavior occurred the higher parents' stress level reached [5]. The level of stress and depression of subjects' parents cause low of their psychological well-being (PWB) [6]. Beside that situation, the high negative stigma level to subjects makes parents' subjective well-being (SWB) low as well [7]. Research finding indicated that the low parents' $S W B$ drawn from the scores of depression and anxiety [8]. This research also found that 79\% caregiver of children with intellectual disability also tend to have depression' risk [3].

SWB defined as affective and cognitive evaluation of a person through his/her life [9]. Someone's life evaluation in subjective well-being includes emotional reaction to some events in life as cognition value over satisfaction and life fulfillment [9]. Regarding the existence of children with intellectual disability [10] pointed that the present of the children to their parents causes various negative feelings such as sadness, confusion, anxiety, and also shock. Parents feel worry about the future and also self dependency of their children mainly when they are already passed away [10]. Parents' anxiety also happened when their children become the object of bullying from the people around them [10]. Finding in the study reflects that the existence of children with intellectual disability influences their parents' SWB.

The result of studies done previously indicated that parents' $S W B$ were low while we know that parents' SWB level influences children' development. According to Benjak, Mavrinac, \& Simetin parents' good physical health condition and level SWB are needed to be able to nurse, to secure and to educate children with intellectual disability. Research conducted by [11] showed that parents happiness (especially mother) as a strong predictor to the development of emotional and cognitive ability of their children. Goodman and Gotlib [12] revealed that depression which experienced by a mother influence to the function and child's development. This depress condition could cause a child having a bigger psychopathology risk.

Low parents' SWB caused by the perception to 
stressor, in which this attitude influences the coping strategy used [13], [14] [15] and coping use influences $S W B$ [16][17][14]. Finding in Lovez et al. study to parents of children with delay development showed that strategy problem focus coping influenced SWB significantly compared to emotional focus coping [13]. Research's result of Hayat and Zafar indicated there was significant correlation between PWB and coping strategy [17]. Parent who relied on active avoidance coping were more in number and reported having lower PWB level [17].

Self-compassion is one of factors that regarded influences SWB [18]. The result of those studies showed that self-compassion was the factor that had important role in individual subjective well-being development. Selfcompassion can be seen as individual emotional regulation strategy to overcome any difficulty situation through self consciousness along with self caring, understanding and open-minded to the community [18]. Parents of children with intellectual disability are difficult to be overt to their community moreover they are sometimes blaming themselves. The research done by Sumiati concluded 50\% of parents were having negative belief system related to the birth of children with intellectual disability, they felt embarrassed, sad, and guilty, they believed that children with intellectual disability that they had were disgrace, curse, karma and yakin anak tunagrahita sebagai aib, kutukan, karma, or enen warning from Allah [19]. These false feelings and perceptions and also negative beliefs can make parents find difficulties to carry out emotional regulation as selfcompassion.

Recent studies that discussed about SWB showed that SWB was influenced by coping strategy and self compassion. Meanwhile, research done by Allen and Laery tried to comprehend self compassion and coping strategy, but the finding had not indicated any strong evidence to conclude the type of coping strategy influenced self compassion level [20]. This research aim to verify that self compassion can mediate the influence between coping strategy (PFC and EFC) to SWB.

\section{METhodS}

\section{Participants}

Participants in this research are 141 parents but only 136 taken for data. Participants taken from inclusive school for children with special needed (SLB) in Jakarta and South Tangerang area and some from organization called POTADS (the community of parents of children with down syndrome). Based on gender, participants consists of 46 fathers and 90 mothers. 47 participants are the first child, 48 second child, 31 the third, 8 the fourth, one person id the fifth, and one the seventh. Based on salary, there are 5 participants who get under one million rupiahs monthly, 45 participants get 1-2 millions, 42 get 3-4 millions, 25 get 5-6, and 19 participants get more than 7 millions.

\section{Measures}

\section{Subjective Well-Being scale}

This scale consists of two dimensions they are cognitive and affective. For cognitive dimensions researcher conducts adaption to The Satisfaction With Life Scale
(SWLS) that developed by [21]. This scale consists of five items. In this scale researcher makes measurement with four choice answers, they are strongly disagree (SD), disagree (D), agree (A), strongly agree (SA). Meanwhile for affective dimensions, researcher performs adaptation to Scale of Positive and Negative Experience (SPANE) which developed by Diener and Robert Biswas-Diener. This scale consists of six items of positive affects and six negative affects. Researcher makes measurement for this scale with four choice answers, never $(N)$, rare $(R)$, often $(O)$, and always $(A)$. Instrument scoring technique uses 1 for never, 2 for rare, 3 for often, and 4 for always, so the bigger SWB's scores reflects the higher SWB's condition.

\section{Self Compassion Scale}

Researcher adapt to Self-Compassion Scale (SCS) which developed by [18]. This measurement tool consists of three dimensions that divided into six subscales. Each dimensions has one subscale for favorable items and one subscale for non-favorable items. The number of scales are 26 items. Researcher makes measurement for this scale with four choice answers, never $(N)$, rare $(R)$, often $(O)$, and always (A) with scoring 1, for $N, 2$ for $R, 3$ for $O$ and 4 for $A$, so that the bigger self-compassion scores indicates the higher self-compassion level.

\section{Coping Strategies Scale}

Researcher adapt to Ways of Coping which developed by [22]. This measurement tool consists of 49 items that grouped to eight subscales they are confrontive coping, distancing, self-controlling, seeking social support, accepting responsibility, escape-avoidance, plan-full problem solving, and positive reappraisal. In this scale researcher makes measurement with four choice answers, never $(N)$, rare $(R)$, often $(O)$ and strongly often $(S O)$. Scoring given by 1 point for never, 2 for rare, 3 for often, and 4 for strongly often, so that the bigger the scores coping strategy type indicates the higher one's coping strategy type.

\section{Data Analysis}

All instruments that used in this research have passed validity test. Validity test done using confirmatory factor analysis (CFA) LISREL 8.7 (Linear Structural Relationship) program. Data obtained is proceeded using path analysis model and software M-Plus 7.4.

\section{RESULT AND DISCUSSION}

Result. Generally the level of parents' SWB some are in high category (51\%) and some are in low category (49\%). Based on gender, fathers' group SWB and mothers', group $S W B$ are in the same level, that is 50\% fathers' group are in low SWB and 50\% are in high; and 50\% mothers' group are in high level of $S W B$ and $50 \%$ are in low category. The rate of male's $S W B$ is 49,88 with standard of deviation 8,35; whereas female's group $S W B$ rate is 49,13 with standard of deviation is 8,87. The t-test result indicates the difference between male and female group is not significant $t(134,2)=0,472,(p>0,05)$.

Analysis result of model (theory) is fit with hypothesis, it is the influence of problem focus coping and 
emotional focus coping to subjective well being with self compassion as mediator, chi-square value $=0,000 ; d f=$ 0; $P$-value $=0,0000 ;$ RMSEA $=0,000, C F I=1,000$ and $T L I=1,000$. The result shows RMSEA is already below 0,05, criteria CFI and TLI are one. Therefore model (theory) that hypothesized is fit with data. Below is figure of model.

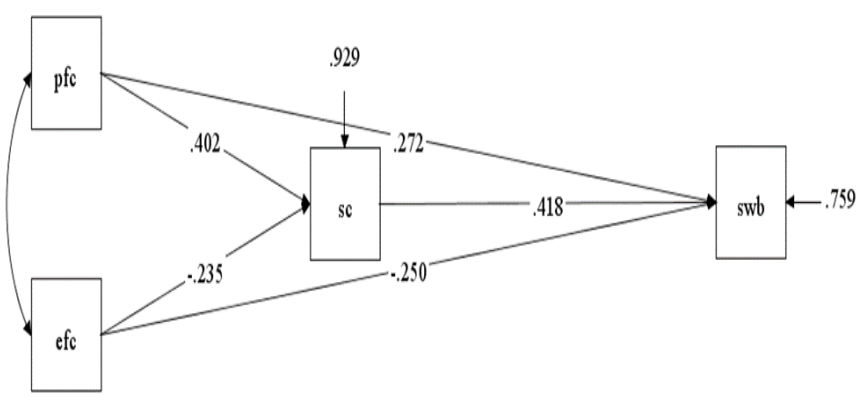

Figure 1

Research Model

Table 1 shows that only problem focus coping (PFC) variable that hs significant influenced to self compassion. PFC has 0,402 positive coefficient and t-value is 3,217. This finding can be assumed that the bigger parents' $\mathrm{PFC}$ the higher their self compassion and those two can increase subjective well being significantly. Emotional focus coping has negative coefficient that is $-0,235$ and $t-$ value $-1,843$. This value shows that emotional focus coping variable doesn't have significant influence to selfcompassion.

\section{Table 1}

Coefficient influence Exogenous Variable's track (Problem Focus Coping and Emotional Focus Coping) to Endogenous Variable (Subjective Well Being) with Self Compassion as Mediator

\begin{tabular}{llllll}
\multicolumn{6}{c}{ (Subjective Well Being) with Self Compassion as Mediator } \\
\hline $\begin{array}{l}\text { Variable } \\
\begin{array}{l}\text { Self Compassion } \\
\text { On }\end{array}\end{array}$ & coefficient & S.E. & $\begin{array}{l}\text { T- } \\
\text { Value }\end{array}$ & $\begin{array}{l}\text { Two- } \\
\text { Tailed } \\
\text { P-Value }\end{array}$ & Exp \\
\hline Problem Focus Coping & 0,402 & 0,125 & 3,217 & 0,001 & $\checkmark$ \\
Emotional Focus Coping & $-0,235$ & 0,128 & $-1,843$ & 0,065 & X
\end{tabular}

Subjective Well Being On

\begin{tabular}{lccccc} 
Self Compassion & 0,418 & 0,071 & 5,864 & 0.000 & $\checkmark$ \\
Problem Focus Coping & 0,272 & 0,120 & 2,275 & 0.023 & $\checkmark$ \\
Emotional Focus Coping & $-0,250$ & 0,117 & $-2,136$ & 0.033 & $\checkmark$ \\
\hline
\end{tabular}

Explanation: $\sqrt{ }=$ significant $; X=$ not significant

On table 2, seen that self compassion along with problem focus coping and emotional focus coping can explain subjective well being 0,241. Whereas variant from self compassion variable can be explained by problem focus coping and emotional focus coping that is 0,071 but the influence of problem focus coping and emotional focus coping are not significant.
Table 2

Contribution of PFC and EFC to SWB

\begin{tabular}{|c|c|c|c|c|c|}
\hline $\begin{array}{l}\text { Observed } \\
\text { Variable }\end{array}$ & Coefficient & S.E. & $\begin{array}{l}\text { T- } \\
\text { Value }\end{array}$ & $\begin{array}{l}\text { Two- } \\
\text { Tailed } \\
\text { P- } \\
\text { Value }\end{array}$ & Exp. \\
\hline Self Compassion & 0,071 & 0,043 & 1,679 & 0.093 & $\bar{x}$ \\
\hline $\begin{array}{l}\text { Subjective Well } \\
\text { Being }\end{array}$ & 0,241 & 0,064 & 3,775 & 0.000 & $\sqrt{ }$ \\
\hline
\end{tabular}

On table 3 can be shown that there is indirect impact of problem focus coping to subjective well-being and also the impact of problem focus coping to self-compassion (mediator). Total coefficient of problem focus coping's impact to subjective well-being is 0,440 and it is significant. The impact of problem focus coping to subjective well being divided into two parts, those are direct impact with significant value is 0,272 and indirect impact by self-compassion is 0,168 and significant. Therefore, it comes to conclusion that the biggest impact that influences subjective well-being is direct impact of problem focus coping to subjective well-being which value is 1,62 (it is one and half times stronger than indirect impact). However, both theories are accepted. Total coefficient of emotional focus coping's impact to subjective well-being is $-0,349$ and significant. Emotional focus coping's impact to subjective well-being is divided into two, they are -0,250 significant direct impact and indirect impact through self compassion with value $-0,098$ and not significant. It can be concluded that emotional focus coping has direct impact to subjective well being, but it doesn't have any direct impact through selfcompassion.

Table 3

Indirect Impact of PFC and EFC toward SWB

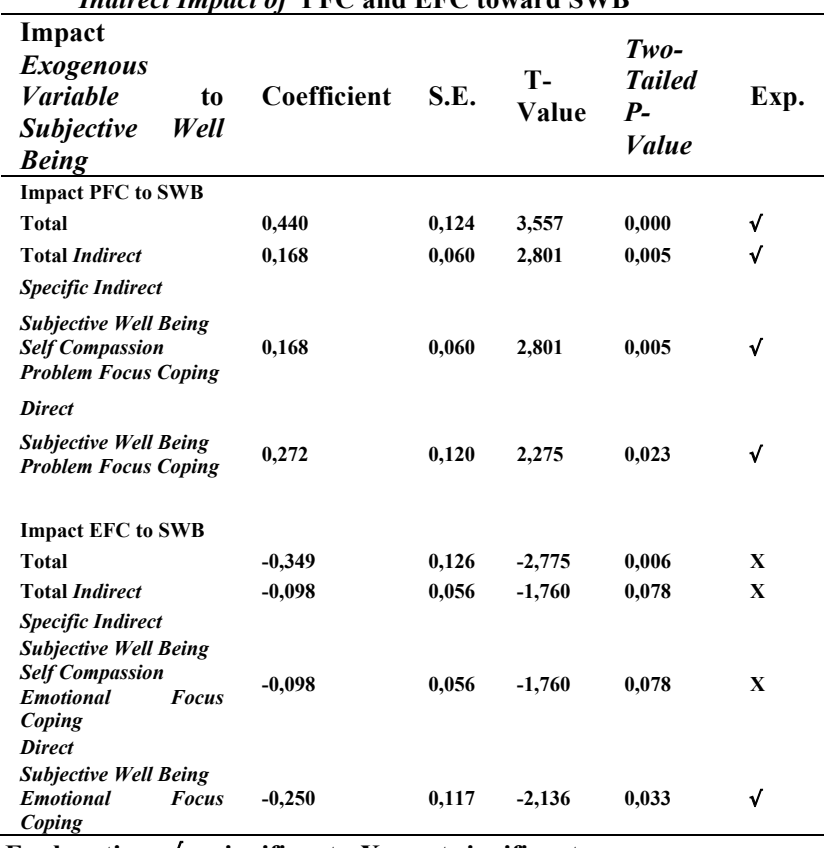

Explanation: $\sqrt{ }=$ significant $; X=$ not significant

Discussion. SWB level of father and mother is significantly not different $(t=0,472<1,96)$. It reflects that both father or mother has the same SWB level. Although mother is regarded as the one who has the most interaction with the children, in fact the existence of 
children with intellectual disability influences parents' SWB condition, father and mother. Father and mother, both of them should hand in hand together in taking care, educate, and also encounter negative stigma that might come from society. Therefore both father and mother need much effort to take care of children with intellectual disability.

The result of analysis shows that the influence of problem focus coping and emotional focus coping to subjective well-being is mediated by self-compassion. Problem focus coping and emotional focus coping also self-compassion have significant direct impact. Selfcompassion has bigger direct impact, that is 0.418 $(t=5,864>1,96)$. This finding reflects that this variable is important to create SWB. When parents begin to accept the situation and they are focus on how to deal with it and stop judging themselves, this way can increase SWB. In other words, no matter how hard the situation they faced engaging their children with intellectual disability they are still can be wise and positive. Parents' success in changing a negative situation to a positive meaning can help to increase their SWB. Finding of this research is in line with the result study of Neff which showed that selfcompassion has important part for parents of children with autism . Self-compassion can be as emotion regulation towards any unexpected event so that it can create a better new perspective [18].

PFC variable has $0,272 \quad(t=2,275>1,96)$ significant direct impact. It reflects that the more PFC coping strategy used parents' SWB get higher. Whereas EFC has $-0.250 \quad(p=0.033<0.050)$ significant negative direct impact. It means the higher EFC used the lower SWB. Finding of this research is in line with result study of Smedema, Catalano and Ebener which showed significant positive relation between positive coping with SWB negative relation between negative coping with SWB . Finding in this research indicates that parents that have problem focus coping try to find some support, they try to change the situation and willing to take the risk. They take full responsibility as parents of children with intellectual disability, they also seek for the best solution and they are able to set the plan to overcome the problem. Meanwhile emotional focus coping strategy, parents tend to avoid reality. They are focus on their own feeling and don't want to find any solution. Therefore parents who have problem focus coping strategy have a higher SWB level compare to parents who use emotional focus coping strategy.

PFC has significant indirect contribution to SWB through self-compassion, whereas EFC contribution is not significant. This finding reflects that PFC take parents' self-compassion whilst EFC is not significantly taking parents to self-compassion. This thing can be understood that through PFC parents think and find solution that can help them to overcome any problem emerge relates to children with intellectual disability. Indirect impact reflected by using PFC parents stop blaming themselves and be focus on finding efforts to get the best solution whilst parents that use EFC tends to struggling with their feeling within, though there is any effort to find the positive way but that effort is not in line with getting an effective solution, hence EFC's contribution to self compassion is not significant.

\section{CONCLUSION}

Finding in this research shows that parents who use PFC and self compassion can reach a better SWB compared to those who use EFC. By using EFC parents are difficult to do self compassion and SWB. Parents who use EFC strategy tend to struggling with their own feeling, they are not capable to see the positive aspect that bring them to an effective solution. Whilst parents who use PFC tend to think of any action plan that can change or get an effective solution to the problem they are facing.

\section{REFERENCES}

[1] J. L. Taylor, J. S. Greenberg, and F. J. Floyd, "Siblings of Adults With Mild Intellectual Deficits or Mental Illness: Differential Life Course Outcomes," vol. 22, no. 6, pp. 905914, 2008.

[2] Kemenkes, "Desember-hari penyandang cacat sedunia," Pus. data dan Informasi Kementerian Kesehatan RI, no. Penyandang disabilitas pada anak, pp. 1-8, 2014.

[3] M. N. Mbugua, M. W. Kuria, and D. M. Ndetei, "The Prevalence of Depression among Family Caregivers of Children with Intellectual Disability in a Rural Setting in Kenya," vol. 2011, 2011.

[4] X. An, J. Rojahn, T. W. Curby, and Y. Ding, "Psychometric properties of the Chinese Behavior Problems Inventory-01 in children and adolescents with or at risk for intellectual disabilities," Res. Dev. Disabil., vol. 36, pp. 256-263, 2015.

[5] A. M. Ritzema and I. E. Sladeczek, "Stress in Parents of Children with Developmental Disabilities over Time Abstract," vol. 17, no. 2.

[6] J. M. N. Cramm, "Psychological well-being of caregivers of children with intellectual disabilities : Using parental stress as a mediating factor Psychological well-being of caregivers of children with intellectual disabilities : Using parental stress as a," J. Intellect. Disabil., no. February 2016, 2011.

[7] S. Werner and C. Shulman, "Subjective well-being among family caregivers of individuals with developmental disabilities, The role of affiliate stigma and psychosocial moderating variables.pdf." pp. 4103-4114, 2013.

[8] N. Boromand, M. Narimani, and T. Mosazadeh, "Comparing the psychological well being factors among the parents of the mentally retarded children with those of the normal children," vol. 21, pp. 1-8, 2014.

[9] E. Diener, R. E. Lucas, and S. Oishi, "Edited by Foxit Reader Copyright(C) by Foxit Corporation,2005-2010 For Evaluation Only.," no. C, pp. 2005-2010, 2010.

[10] R. D. Ratnasari, "GROUP DAN PENDAPATAN TERHADAP SUBJECTIVE WELL-BEING ORANG TUA ANAK TUNAGRAHITA," Skripsi, p. 2017, 2017.

[11] M. Malmir, M. Seifenaraghi, D. D. Farhud, G. A. Afrooz, and M. Khanahmadi, "Mother???s happiness with cognitive Executive functions and facial emotional recognition in school children with down syndrome," Iran. J. Public Health, vol. 44, no. 5, pp. 646-653, 2015.

[12] S. H. Goodman and I. H. Gotlib, "Risk for Psychopathology in the Children of Depressed Mothers : A Developmental Model for Understanding Mechanisms of Transmission," vol. 106, no. 3, pp. 458-490, 1999.

[13] T. Clifford and V. Lopez, "Parental Stress and Coping in Families of Children With and Without Developmental Delays," vol. 14, no. 2, 2008.

[14] Y. Lau, P. H. Tha, D. Fu, K. Wong, Y. Wang, Y. Wang, and P. K. Yobas, "Different perceptions of stress , coping styles, and general well-being among pregnant Chinese women: a structural equation modeling approach," pp. 71-78, 2016.

[15] C. Chen and C. Chen, "The Role of Resilience and Coping Styles in Subjective Well-Being Among Chinese University Students," Asia-Pacific Educ. Res., vol. 25, no. 3, pp. 377$387,2016$.

[16] V. Kumar, "Psychological Stress and Coping Strategies of the 
Parents of Mentally Challenged Children," vol. 34, no. 2, pp. 227-231, 2008.

[17] I. Hayat and M. Zafar, "Relationship between Psychological Well-Being and Coping Strategies among Parents with Down syndrome children," vol. 5, no. 7, pp. 109-117, 2015.

[18] K. Neff, "Self-Compassion: An Alternative Conceptualization of a HealthyAttitudeToward Oneself," no. August 2002, pp. 85-101, 2003.

[19] N. T. Sumiati, "Hubungan antara Family Belief Systems dan
Tipe Pola Asuh tehadap Behaviour Problems Anak dengan Down syndrome," Tazkia, 2017.

[20] A. B. Allen and M. R. Leary, "Self-Compassion, Stress , and Coping," vol. 2, pp. 107-118, 2010.

[21] E. Diener, R. A. Emmons, R. J. Larsen, and S. Griffin, "The Satisfaction with Life Scale.pdf." pp. 71-75, 1985.

[22] R. S. Lazarus, "Coping Theory and Research : Past, Present, and Future," vol. 247, pp. 234-247, 1993. 